\title{
It Gets Better with Time: The Perception of Stigma Among Older Adults with Chronic Physical Illness and in Recovery from Mental Health Condition
}

\author{
Angela J. Johnson ${ }^{* a}$ \& Kyaien O. Conner \\ ${ }^{a}$ Department of Psychology, Mary Baldwin University, Staunton, VA \\ ${ }^{b}$ Department of Mental Health Law and Policy, University of South Florida, Tampa, FL \\ bttps:// doi.org/10.33697/ ajur.2019.009 \\ Student:johnsona1738@marybaldwin.edu* \\ Mentor:koconner@usf.edu
}

\begin{abstract}
Older adults are a vulnerable population who are more susceptible to developing mental health conditions, and the symptoms are often exacerbated by the co-occurrence of various physical health complications. Despite available evidence-based interventions, many older adults neglect to utilize mental health services, due to the stigmatization of mental health conditions. Limited research has focused on the unique experiences of older adults who have overcome the adverse effects of stigma, have sought help for their mental health condition and are currently in recovery. There are even fewer studies that have addressed perceptions of stigma among older adults in recovery from a mental health condition who are currently living with a chronic physical illness. The present study investigated the unique experiences of seeking professional mental health services and the perceptions of stigma among nine older adults living with a chronic physical illness and currently in recovery from a mental health condition utilizing semi-structured interviews. Through an in-depth thematic analysis of the data, four over-arching themes were identified: Resilience from the Stigma of a Mental Illness, Community Engagement, Cultural Barriers and Social Support System. Findings from the current study suggest that older adults who have previously experienced a mental health condition and were able to overcome the stigma of their condition, were more likely to seek professional help. Additionally, engaging in community engagement programs to help other older adults who are currently experiencing acute mental health conditions seemed to reduce perceptions of stigma and positively impacted participants self-esteem and overall outlook on life.
\end{abstract}

\section{KEYWORDS}

Stigma; Perception; Older Adults; Mental Health Condition; Co-Occurring Disorders

\section{INTRODUCTION}

Older adults are the fastest growing segment of the US population, and by the year 2040, the number of adults 65 and older is projected to be 80 million. ${ }^{1}$ Older adults are susceptible to the development of various mental health conditions. Researchers' have projected approximately 15 million older adults will have a diagnosable mental health condition by the year $2030.2,3$ However, due to the high percentage of mental health conditions going under-diagnosed in the older adult population, these future prevalence estimates are likely an under-estimate of what we can expect. ${ }^{1}$

Depression is the most prevalent mental health condition among older adults, affecting one in ten individuals. ${ }^{4-7}$ Depression is characterized by intense feelings of sadness, disturbed sleep or appetite, fatigue and poor concentration. ${ }^{8}$ According to the Diagnostic and Statistical Manual of Mental Disorders, depression is diagnosed when the changes in one's personal, vocational, social and health functions are clinically significant, lasting for a minimal duration of two weeks ${ }^{9}$. Although the onset of depression can develop during any stage in life, depression often goes undiagnosed and undertreated well into later adulthood ${ }^{6}$. Late-life depression is associated with longer hospital stays, functional limitations, higher mortality rates, and higher medical comorbidities in comparison to other medical disorders. ${ }^{6,10}$ Other common mental health conditions in this population include: schizophrenia, delusional disorders, bi-polar disorder, anxiety and depression. ${ }^{4,6}$ The debilitating effects of mental health conditions include: substantial loss in the quality of life in older adults, financial burden and the disproportionately higher mortality rates of those with a mental health condition compared to those without mental health conditions. ${ }^{11,12}$

Another issue faced by older adults living with a mental health condition is the exacerbation of mental health symptoms due to the co-occurrence of a chronic physical illness. The co-occurrence of physical and mental health conditions is frequent in older adults; approximately $80 \%$ of older adults have at least one chronic physical health condition, and $50 \%$ have two or more chronic 
physical health conditions, which are often accompanied with years of pain and loss of function. ${ }^{4}$ Individuals with a mental health condition have an increased risk for the development of chronic physical medical conditions, compared to those without a mental health condition. ${ }^{13}$ Individuals with co-occurring physical and mental health conditions face more prejudicial attitudes from members in their communities, and are more likely to avoid utilizing mental health services compared to individuals with solely a mental health condition. ${ }^{14}$ Clinicians are often guided by the negative stereotypes of mental health conditions, and are more likely to treat physical health complications of their patients with a mental health condition less thoroughly and effectively. 15 Stigma continues to be a world-wide health concern and older adults living with a mental health condition continue to be victimized by the effects of stigma. ${ }^{14}$ Stigma regarding a mental health condition can be divided into three components: public, perceived and internalized-stigma. Public stigma refers to the prejudicial attitudes of members in communities toward individuals with a mental health condition. ${ }^{16}$ Perceived-stigma occurs when stigmatized individuals believe that others hold negative stereotypes toward individuals with a mental health condition. ${ }^{17}$ Internalized stigma occurs when stigmatized individuals believe the stereotypes about individuals with a mental health condition are true, and apply those beliefs to how they feel about themselves. ${ }^{18}$

Stigma associated with a mental health condition is associated with mistreatment, rejection, social distancing, fear and ill treatment from members in society. ${ }^{19,} 20$ Individuals who may benefit from mental health treatment choose not to pursue services or begin treatment but drop-out prematurely to avoid prejudices and discrimination associated with having a mental health condition. ${ }^{21-24}$ Help-seeking behavior is often seen as a sign of personal weakness, contributing to the reason why many individuals seek professional help as a last resort. ${ }^{20}$ Although research suggests stigma associated with the utilization of mental health services is a greater barrier than the condition itself, there are individuals who have found ways to overcome those barriers. ${ }^{20}$

Current literature on the stigmatization of a mental health condition frequently highlights the perception of stigma among individuals currently experiencing a mental health condition, but such research often omits the population of older adults in recovery from a mental health condition. There are even fewer studies that have addressed perceptions of stigma among older adults in recovery from a mental health condition who are currently living with a chronic physical illness. The present study begins to address this gap in the literature by providing a deeper understanding of the perception of stigma among older adults who selfidentified as being in recovery from a mental health condition. This research is central toward helping us understand the mechanisms through which some vulnerable populations of elders have been able to break through the barriers of stigma and engage in professional mental health services. Information from this investigation can assist in identification of targets toward helping other vulnerable populations of older adults combat the effects of stigma.

\section{METHODS}

The present study investigated the unique experiences of seeking professional mental health services and the perceptions of stigma among older adults living with a chronic physical illness and in recovery from a mental health condition. Qualitative research methodology was used to gain an in-depth understanding and to explore the unique experiences of the study participants. Qualitative data has been widely used in the field of psychology to assess various mental health related topics ${ }^{25}$. Semi-structured interviews were administered to allow participants to give a broad and detailed description of their experiences of stigma. The use of semi-structured interviews allows for the emergence of themes that may not be predicted ahead of time by the researcher due to the participant's opportunity to speak freely in a comfortable environment ${ }^{26}$.

\section{Setting and participants}

Study participants were recruited from the "Enhancing the Care Transitions Intervention to Facilitate Wellness and Reduce Hospital Readmissions among Older Adults with a Co-occurring Mental Health Diagnosis” pilot study (PI: Kyaien Conner). All participants (N=9) in this study responded to flyers located at the local Area Agency on Aging (AAA) asking for older adults who were in recovery from a mental health condition and were interested in being trained to work with other older adults currently experiencing acute mental health conditions. Inclusion criteria included older adults who: (a) were 55 years of age or older; (b) self-identified as having a previous mental health condition and currently being in recovery; and (c) self-identified as having a current chronic physical illness. All participants were informed about the voluntary nature of the study and received a written informed consent document to read prior to study engagement. Participants were told that their participation in this study would in no way affect their participation in the larger ENHANCE study. All activities complied with the University of South Florida's provisions for the ethical conduction of research with human subjects (CR1_Pro00025016).

\section{Demographical characteristics}

Participants self-reported items regarding their identity including age, race, ethnicity, education, gender, marital status, and treatment utilization status. 


\begin{tabular}{|c|c|c|}
\hline Characteristic & $\mathbf{N}(\%)$ & Mean \\
\hline Age & & 65.1 \\
\hline $50-60$ & $4(44.4 \%)$ & \\
\hline $61-70$ & $2(22.2 \%)$ & \\
\hline $71-80$ & $3(33.3 \%)$ & \\
\hline \multicolumn{3}{|l|}{ Race/Ethnicity } \\
\hline Black/African American & $1(11.1 \%)$ & \\
\hline Non-Hispanic White & $5(55.6 \%)$ & \\
\hline Hispanic & $3(33.3 \%)$ & \\
\hline \multicolumn{3}{|l|}{ Gender } \\
\hline Female & $7(77.9 \%)$ & \\
\hline Male & $2(22.2) \%$ & \\
\hline \multicolumn{3}{|l|}{ Marital Status } \\
\hline Married & $3(33.3 \%)$ & \\
\hline Divorced & $4(44.4 \%)$ & \\
\hline Widowed & $1(11.1 \%)$ & \\
\hline Single/Never Married & $1(11.1 \%)$ & \\
\hline \multicolumn{3}{|l|}{ Education Level } \\
\hline Some College & $4(44.4 \%)$ & \\
\hline Bachelor's Degree or Higher & $5(55.6 \%)$ & \\
\hline \multicolumn{3}{|l|}{ Mental Health Treatment } \\
\hline Never & $4(44.4 \%)$ & \\
\hline Past 1-5 Months & $3(33.3 \%)$ & \\
\hline Past 6-11 Months & $0(0 \%)$ & \\
\hline Over 1+Years Ago & $2\left(22.2^{\%} \%\right)$ & \\
\hline \multicolumn{3}{|l|}{ Individuals in Household } \\
\hline 1 & $5(55.6 \%)$ & \\
\hline 2 & $4(44.4 \%)$ & \\
\hline $3+$ & $0(0 \%)$ & \\
\hline
\end{tabular}

Table 1. Respondent Characteristics.

\section{Semi-structured interview}

Interviews were conducted with all the participants $(\mathrm{N}=9)$ at the local AAA in a small conference room. Interviews lasted approximately 30 minutes and followed a semi-structured interview format. The use of open-ended questions allowed for a broad and detailed description of participants' experiences with mental health service utilization and stigma. To assist in the structure of the interview, additional probing questions were asked to elicit further in-depth responses if necessary. Examples of questions asked included: "Can you tell me when you experienced a mental health disorder?"; "Can you tell me about some things that encouraged and discouraged you to seek treatment?"; "Can you describe a time in which you felt isolated, or stopped participating in certain activities because of your mental illness?"; and "Have you ever felt mistreated because of your mental illness, describe what happened?" Questions were designed to cater to the older adult population and to ensure comprehension of all questions asked. To show appreciation for their assistance in the study, participants received a monetary compensation of $\$ 25.00$ after completion of the interview. 
Data Analysis

Qualitative techniques were utilized in efforts to attain detailed description and give a voice to older adults with a co-occurring mental health diagnosis and to hear their unique experiences regarding the stigmatization of mental health conditions. This framework is used frequently throughout the field of Psychology. In this study, it will grant researchers with the opportunity to grasp the meanings, motives and patterns of perceived stigma in older adults with a co-occurring mental and physical condition that usually goes unnoticed in various standardized approaches, such as surveys. ${ }^{27}$ To provide rich descriptions of the complex phenomena of stigma, thematic analysis was utilized to assess the data. The six-phase guide suggested by Braun and Clarke was used to successfully analyze the qualitative data. ${ }^{25}$ Audio-recorded interviews were transcribed and re-read to ensure for accuracy. Printed versions of the transcriptions were read through thoroughly to familiarize ourselves with the data and noted for initial ideas. Subsequently the transcriptions were coded line by line, using the participants' words in attempt to summarize a detailed description of responses. The codes from each transcription were extracted from the data and collated into groups based on their similarities and categorized into potential themes. ${ }^{25}$ The potential themes were examined for coherent patterns and refined to create overarching themes that best captured the context of the entire data set. A final codebook was created; vivid quotes were extracted from the transcriptions that best related to the literature and answered the research questions. ${ }^{25}$ Despite a small sample size, saturation of the data was met with 9 interviews and at such time no further interviews were conducted.

\section{RESULTS}

As shown in Table 1, participants included 9 older adults (mean age of 65.1). The majority of the participants identified as NonHispanic White Females (55.6\%) who were divorced (44.4\%), received mental health treatment within the past year $(77.8 \%)$ and lived by themselves (55.6\%). All participants graduated from high school and attended at least some college, with some (55.6\%) having a bachelor's degree or higher. As shown in Table 2, participants had one or more mental health conditions. Depression was the most prevalent $(88.9 \%)$ mental health condition, followed by anxiety $(22.2 \%)$, bi-polar disorder $(11.1 \%)$, and schizophrenia $(11.1 \%)$. All participants reported having one chronic physical illness. The most prevalent physical illness was diabetes $(33.3 \%)$, followed by cancer $(22.2 \%)$ chronic back pain $(22.2 \%)$, lupus $(11.1 \%)$ and cardiovascular disease $(11.1 \%)$.

\begin{tabular}{|c|c|}
\hline Mental and Physical Health Condition & $\mathrm{N}(\%)$ \\
\hline Mental Health Condition & \\
\hline Depression & $8(88.9 \%)$ \\
\hline Anxiety & $2(22.2 \%)$ \\
\hline Schizophrenia & $1(11.1 \%)$ \\
\hline Bi-Polar Disorder & $1(11.1 \%)$ \\
\hline & \\
\hline Chronic Physical Illness & \\
\hline Diabetes & $3(33.3 \%)$ \\
\hline Cancer & $2(22.2 \%)$ \\
\hline Chronic Back Pain & $2(22.2 \%)$ \\
\hline Lupus & $1(11.1 \%)$ \\
\hline Cardiovascular Disease & $1(11.1 \%)$ \\
\hline
\end{tabular}

Table 2. Summary of Participants Health Status.

\section{Interview Results}

Results of the thematic analysis yielded four over-arching themes that aid in our understanding of the perceptions of stigma of older adults in recovery of a mental health diagnosis and living with a chronic physical illness. These themes included: 1.) Resilience from the Stigma of Mental Health Conditions, 2.) Community Engagement, 3.) Cultural Barriers and 4.) Social Support System. See Table 3 for a description and overview of identified themes. Important quotes were extracted from the study participants' transcripts which best related to the identified themes. Study participants were given pseudonyms to protect their anonymity. 
Resilience from the Stigma of Mental Illness

All participants reported living with stigma of a mental health condition and not having someone to relate to, to confide in. Participants' stigmatizing experiences were manifested in the forms of isolation, non-disclosure of mental health status and decreased help seeking behavior. When asked if they have ever felt mistreated from having depression, Sarah, a sixty-four-year-old, White woman stated, "No because I didn't share it". Some participants felt uncomfortable around their peers because of their mental health state. Ashley, a sixty-year-old white woman stated, "... if this was not anonymous, you know if my name was given, I probably wouldn't want to give this information."

Many participants were deterred from seeking professional treatment, "I don't, I never thought that I needed it [treatment]...I would cry and that was it. I got it out of my system." Some of the participants even began to accept the stigmatizing mistreatment from their peers. Grace, a sixty-year-old White woman stated, "It [Depression] just seemed so engrained in a part of who I was it didn't seem like much that I needed to discuss or that I thought that it wasn't anything that anyone was able to fix." She further stated, "In these days when it happens I kind of laugh, depending on who it is. At the church where I go, this older man, he is the pastor. He learned what I have, and he says oh you're schizo, we had some people over the hill who were Schizo growing up, you are just schizo it is no big deal."

Despite the mistreatment associated with their mental health condition, participants were more receptive toward disclosing their physical health status, but still "felt isolated because of the pain and fatigue I was experiencing". The co-occurrence of mental and physical conditions created some confusion for the participants. Sarah, a sixty-four-year-old, White woman stated she was unsure if the isolation was due to "the physical manifestations of the lupus disease, or because of the depression... I have no idea how to sort those out". Some participants even reported the stigma of their mental health condition surpassed them and affected their loved ones. It wasn't until the involvement of mental health organizations that allowed certain family members to accept the participants. Ashley, a sixty-year-old White woman stated: "There has been a few family members, who didn't understand what it was, and my step-mom said you just need to buck up and you just need to deal with it, that kind of attitude. I had a brother-in-law that said I was being wimpy and all that stuff, but ubh he came around, cus be got hooked up with NAMI (National Alliance for Mental Illness)."

When asked if they ever tried to reach out and confide in others, the participants did not know... "who would I have talked to?" Grace, a sixty-year-old White woman stated, 'No I couldn't of talked to her [mother], I was afraid of the ramifications, and isn't that sad. I really couldn't talk to anybody; I did tried to reach out to talk to friends, but not about this [Depression]. "Ashley, a sixty year-old White woman elaborated: "Because of the stigma, and umm you know, even in our class, people don't understand it and you know they think you know, that there is a tendency for somebody to be violent and they just don't understand it you know. And you know they might think, you know who knows what they think".

Some participants even reported effects of stigma in the form of mistreatment from their psychiatrists, where there were disagreements in treatment services. Sarah, a sixty-four-year-old, White woman elaborated: "T went to the Psychiatrist twice... he did not tell me whether it would have an impact on the chemotherapy that allows me to keep my kidneys. So instead I got mad and went to the library and started researching, I did not take any medication". Ashley, a sixty-year-old, White woman stated:

"I feel like being at a hospital when I was young, I guess being in the hospital and not being treated well, I feel like it had to be more than this. I feel like, that something was gonna come back you know, you know I would get something out of that because I was mistreated."

Despite the negative situations that the study participants experienced, those who acknowledged having a mental health condition were able to overcome the stigma. Participants were able to accept their mental health status and are more comfortable sharing their stories. When asked how their experience with a mental health condition changed over the years Sarah, a sixty-four-year-old White woman reported: "Yeah I don't see myself as depressed anymore". All the participants reported having better experiences with their mental health condition. Grace, a fifty-eight-year-old, white woman stated: "It's gotten a lot better, especially since I've gotten the proper diagnosis. I was diagnosed with Bipolar disorder for a long time, it wasn't until I moved down here, that the true self was becoming about". Andre, a sixty-year-old, African American man stated: "My experiences have definitely become more positive. Umm I'm less likely now to ever want to harm myself or anyone else, you know I'm in a better place. Umm I wake up every morning and I feel great, I feel good, I feel energetic, I feel hey, I'm blessed to be blessed and I want to live you know".

Participants reflected on their past negative experiences from living with a mental health condition and are now more comfortable sharing their stories. Having recovered from their co-occurring mental health diagnosis, participants wished everybody knew at least about mental illness, we could let go of some of the stigma. Gloria, a fifty-four-year-old white woman stated, "I was too fragile to reach out to bardly anybody, and so now being more whole and having gone through process and found ways for self-care, it's easier to share that knowledge, because I have it, and I didn't have it back then." 
Community Engagement

One of the ways participants dealt with their experience with a mental health condition was giving back to the community. Many participants felt "that something compels me to want to help others, and that is what I do, I want to help others". Many participants emphasized how "It is important to help other people to find a way to hold the light and help them find their way out." The desire to give back to community was a recurrent ideology in the study. Ashley, a sixty year-old, White woman stated: "It is just better, I feel like I'm dealing with it you know, and that was one thing I was attracted to this program, because you know I feel like I could help people because I've been through it myself and I'm older and umm I have come to terms with it."

Participants enjoyed the personal benefit from being able to share their stories with others. Participants strongly suggested "the elderly people need that kind of help." "The need to provide emotional support and advice to their peers who are currently experiencing a mental health condition was a pertinent concern amongst the study participants. Andre, a sixty-year old, African American man stated: "It makes me feel good when someone else listens to me and I tell them that um some of my experiences and they ask me well how did you do it". Many participants were eager to provide services so others "don't have to go through what I went through 40 years ago, you know not having someone to relate to, to confide in. Ashley, a sixty-year-old, White woman stated: "I guess my main idea is trying to benefit the other person you know and I guess when, if I am able to do that you know, I would like to see them being healthy and um out of the hospital".

All participants had some form of higher education beyond high school and felt that their education and past "experiences working with the elders" made them especially qualified to help others. Sarah, a sixty-four year-old, White woman stated, "I am already a master trainer for Stanford University chronic disease self-management program, and as program director for the Lupus Foundation, I deal with patients who are in often depressed, and don't know where to turn or can't figure out the solutions having being in that situation, it is important to belp other people find a way to hold the light and to help them find their way out". Victor, a seventy-eight-year-old, Hispanic man stated: "At USF, I went to Stanford to take CDS and PD, it's a training to help people with chronic illnesses and management problems. Uh you coach that, and it was a good experience you know, the elderly people here they need that kind of help, so we went around and talked about chronic diseases and how to manage them and the proper thing and mind and that thing".

All participants of the study reported positive experiences engaging with members of their community who were in the process of recovering from a mental health condition. For many of the participants, involvement in these social programs became a significant part of their everyday life. In addition, many participants even reported receiving appropriate certification and training, allowing them to be better equipped to service their peers.

\section{Cultural Barriers}

Culture and cultural barriers appeared to play a very important role in participants' perceptions of stigma and seeking mental health treatment. It also played a role in how participants verbalized their experience of having a mental health condition. All the study participants who self-identified as Hispanic $(\mathrm{N}=3)$ were uncomfortable to openly acknowledge the presence or history of having a mental health condition. When asked to describe a time when they experienced a mental health condition they responded with "I've never experienced a mental health disorder". However, when asked if they have experienced recurrent episodes of intense feelings of sadness, or other symptoms commonly associated with a mental health diagnosis, the study participants responded and had unique stories to share. Lisa, a sixty-three-year-old Hispanic woman stated: "No I feel like no one can belp me really. You know cus I get depressed sometimes, because like I said my family is very far away or gone away, or so I just keep things to myself".

Participants felt that the experience of symptoms of depression was a normal experience, something that everyone goes through. Participants felt they needed to justify not being depressed. For example, one participant stated she wasn't "depressed I would call it more like I was bored, and I felt that I needed to do something with my life". Sasha, a seventy-four-year-old, Hispanic woman said, "It's not something that I carry with me at all, it is just something that I consider uh normal, you know". Lisa, a sixty-three year old, Hispanic woman stated: "You know I have even heard umm, even in Spanish they say 'If you are gonna cry, cry in your house, when you are alone and nobody sees you or whatever, and then you get over it', or so you don't have to you know, show your emotions that much, you're always being what you don't feel like being."

Culture also played a role in the mental health services individuals engaged in. While all participants identified themselves as in recovery from a mental health condition, participants did not all choose formal professional mental health services as an avenue for treatment. Participants identified themselves as "very family oriented, so no the idea, the thought never crossed my mind. I didn't need it. I had all the support that I needed. "Participants found various non-clinical ways to cope with their mental health conditions.

Participants often looked to family for social support, participated in other activities as an escape mechanism, engaged in community-based activities where they could give to others, or were just content with their emotional state and pushed through it on their own. Victor, a seventy-eight-year-old, Hispanic man stated: "I kind of adapted through it, you know I've come to the conclusion that it is a part of my life, you now I have to deal with it and umm it doesn't bother me you know." 


\begin{tabular}{|c|c|}
\hline Theme w/ Definition & Direct Quote \\
\hline $\begin{array}{l}\text { Cultural Barriers } \\
\text { Cultural customs and beliefs that inhibit } \\
\text { individuals from seeking professional treatment } \\
\text { and disclosure of their mental illness. }\end{array}$ & $\begin{array}{l}\text { PE7: I always look at the positive things, I believe very much in the power of mine, so you got to be positive. You know } \\
\text { whatever happens it happens, it is what it is and that's it. } \\
\text { PE6: I don't know if you know about Cubans, but we're like very family oriented, so no, the idea [mental health } \\
\text { treatment], the thought never crossed my mind. I didn't need it, I had all the support that I needed. }\end{array}$ \\
\hline $\begin{array}{l}\text { Benefit of Social Support } \\
\text { The need to empathize and sympathize with } \\
\text { others about one's problems regarding their } \\
\text { mental health. }\end{array}$ & $\begin{array}{l}\text { PE2: I had a brother-in-law that said I was being wimpy and all that stuff, but uhb he came around, cus he got hooked } \\
\text { up with NAMI. Somehow he got hooked up, ob my nephew got addicted to drugs, and tried to commit suicide, and that } \\
\text { tooke them on a different journey then they were used to, and so through that he got hooked up with NAMI and learned } \\
\text { about addictions and learned about different stuff, and he ended up apologizing to me for picking on me for so many years. } \\
\text { He finally realized it wasn't my fault, so that was nice... } \\
\text { PE4: No in fact, I do think that one of my art teachers, she keyed on to the fact that I was having trouble with life. I } \\
\text { think. a lot of the teachers in high school knew that there was a lot going on with me, then what was showing on the surface, } \\
\text { and she used to do things, like she brought me in a necklace that she macro-made for me... But if anything, I'd have to say } \\
\text { that they had a band around my shoulder because they wanted to }\end{array}$ \\
\hline $\begin{array}{l}\text { Resilience from the Stigma of Mental } \\
\text { Illness } \\
\text { The ability to overcome the barriers associated } \\
\text { with having a mental health condition, and } \\
\text { work toward a state of recovery. }\end{array}$ & 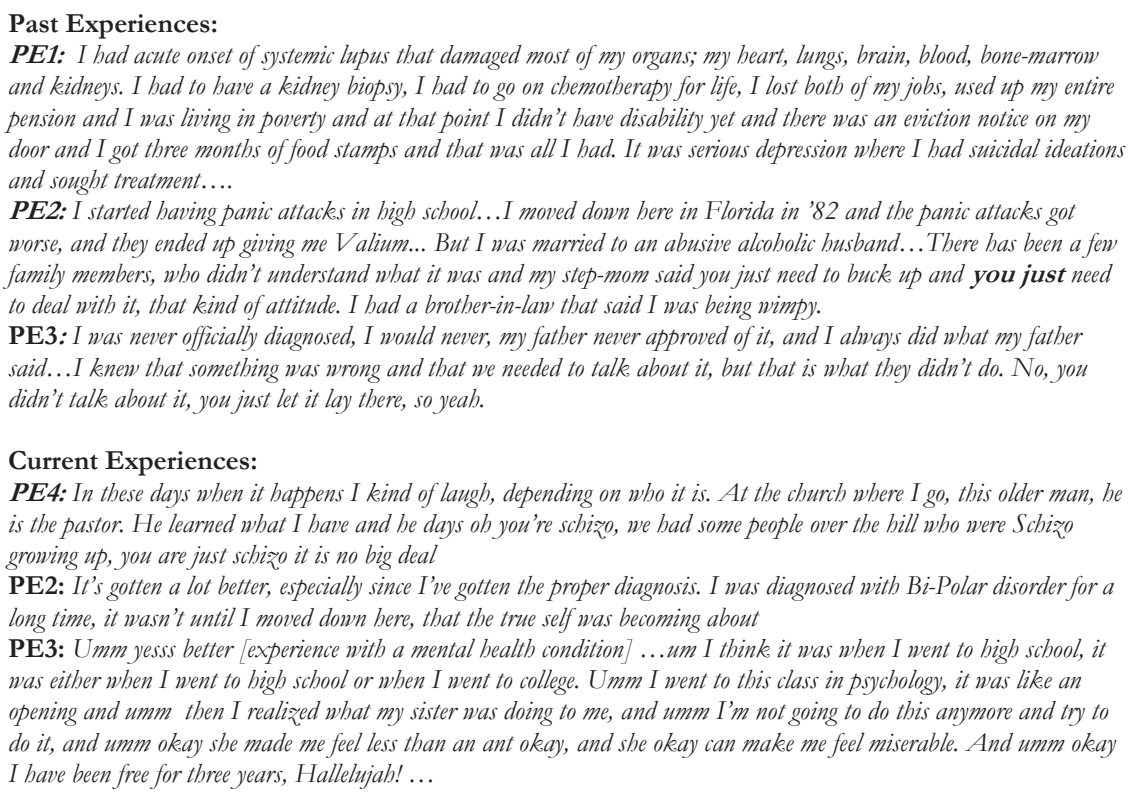 \\
\hline $\begin{array}{l}\text { Community Engagement } \\
\text { The importance of giving back to society and } \\
\text { helping others with a mental illness who are } \\
\text { currently experiencing similar struggles. }\end{array}$ & $\begin{array}{l}\text { PE 6: I figured if I can be a belp to someone, you know I think, on a very selfish way, I'm going to feel good about it to. } \\
\text { It's always like that, you know you bave no idea, you do something for someone and amazingly so, sometime you are the } \\
\text { recipient of that good feeling, because you feel good about it, so it is a combination of things, that you know I don't know if } \\
\text { I'm going to be good at it, but that is why I am interested. I think. my experience with the elders bave been so good, that I } \\
\text { think if I can help someone, I should, I think I should. } \\
\text { PE7: ... the elderly people here they need that kind of help, so we went around and talked about chronic diseases and how } \\
\text { to manage them and the proper thing and mind and that thing. You know I got into matter of balance bere, and I realized } \\
\text { that it does help people, you know they feel every time we coach a course, they come back and say hey bow grateful they are, } \\
\text { and that's a self-reflection. }\end{array}$ \\
\hline
\end{tabular}

Table 3. Sample Responses to the Semi-Structured Interviews.

Social Support System

All of the study participants stressed the importance of having individuals to reach out to in order to cope with their mental health condition. Lisa, a sixty-three year old Hispanic woman stated, "... she [my sister] give me a lot of advice and cause she was, she was married at one time and she left her husband, and she divorced him and she went back to live with my mom and so I rely on her, because she went through what I was gonna go through again". Gloria, a fifty-four year-old, White woman stated: "So everything, came crashing down at that point and I remember calling my sister in the middle of the night, saying I need to go somewhere, because I'm going to burt my kids or something, I need to get out of here, so somehow I ended up at her house and she just took me to a psychiatrist". 
Some participants wanted someone who knew what they were going through in order to overcome a mental health condition. Participants shared stories on how others were unable to understand the extent of their mental health condition. Sarah, a sixtyfour year-old, White woman elaborated, 'I don't think they had the skill or the knowledge or that they [her children] were the right person, the right person to help, because they wouldn't of had that understanding and then I was afraid that they would capture me and make me live with them". Grace, a fifty-eight year- old, White woman stated: "...you never really know the pain anybody else is going through, umm to be able to walk with them and to be able to empathize rather than sympathize, because you, you know what it's like to have a mental illness yourself".

Some participants even talked about the benefits of engaging in support groups for individuals currently experiencing a mental health condition. Andre, a sixty year-old, African American man stated: "People don't think groups work, groups help when you share with other people, A A groups help, if you want to stop smoking cigarettes, nicotine groups help if you want you stop using drugs, there are drugs groups that belp". Ashley, a sixty-year-old, White woman stated: "The BDS A the Bipolar alliance, they have groups and those are great if someone is able to go out and umm be a part of those groups. I know those really help, not to feel isolated when you have umm bi-polar, because that umm a support group just for umm people that have mental illness".

Social support was an important factor in the process of recovering from a co-occurring mental health diagnosis. For many of the participants, the ability to avoid judgment when conveying their thoughts and feeling to others was essential in their path toward recovery.

\section{DISCUSSION}

This study provides critical information on the unique experiences of stigma among older adults who are in recovery from a mental health condition who are currently living with a chronic physical illness. These anecdotal recollections of participants' stigma associated their health status, will help to get a better understanding of the issues associated with mental health treatment utilization. The semi-structured interviews elicited four overarching themes regarding their experiences. Findings in the study echo results in presented in the current literature. Cultural beliefs play a major role in individual perceptions of mental health conditions. Due to the stigma associated with the label of mental health conditions, many Hispanic individuals refer to their mental health condition as mental distress; this term is more congruent with the Hispanic cultural beliefs and ideologies about mental health conditions. ${ }^{28}$ One of the most crucial and challenging stages in recovery of a mental health condition is acceptance. During this stage individuals must overcome their negative self-judgments, develop a positive identity and truly understand the extent of their mental illness. ${ }^{29}$ Hispanic individuals rarely accept the diagnosis of mental health conditions because their perceptions of its etiology often differ from Non-Hispanic individuals. Research shows that the Hispanic communities attribute mental distress to negative childhood experiences, acculturative stress, and relationship and family problems. ${ }^{28}$ A study conducted by Thoman and Suris found that acculturative stress experienced by Hispanic individuals was a significant predictor for psychological distress in comparison to individuals who have not experienced acculturating situations. ${ }^{30}$

Although the study highlighted the cultural barriers faced in Hispanic communities, other cultures attribute the etiology of mental health conditions to distinct factors. For example, in the African American community many individuals justify mental health conditions being caused by super-natural forces. ${ }^{28}$ Studies have also reported high-levels of stigma in the Latino population as a significant predicting factor toward unwillingness to seek treatment. ${ }^{31}$ It is important for mental health clinicians to implement culturally sensitive diagnostic measures and interventions when assessing mental health conditions in individuals from differing cultural backgrounds. Implementing culturally appropriate services will positively impact the under-diagnosis and underutilization of treatment service disparities in the minority population of older adults with a mental health condition.

Participants in the present study all identified unique past experiences where they were mistreated by their friends and family because of the status of their mental health. Stigma can be exhibited from various instances of mistreatment including: the refusal to disclose mental health status, lack of social support from their loved ones, and isolation from members in their community. ${ }^{32}$ Participants of the study, who shared their mental health state to others without a mental health condition, reported perceived lack of understanding and sympathy from the other party. Families and friends of individuals with a mental health condition are also affected by stigma, resulting in their overt act of judgment and ostracism of persons with a mental health condition. ${ }^{32}$

Many participants were reluctant to seek professional mental health treatment. Stigma associated with a mental health condition is known to perpetuate a cycle of disability, halting patient's process of recovery. ${ }^{32}$ Older adults who live in communities who perceive them as "mentally ill" are often more stigmatized than individuals who have other non-mental health conditions ${ }^{33}$. Society often produces stigmatizing reactions toward older adults who have a mental health condition because of their eccentric psychiatric symptoms, social-skill deficits and physical appearances. ${ }^{33}$ In addition, a few of the study participants with acute physical illnesses, neglected to utilize appropriate medical interventions. Failure to disclose physical health complications to the respected clinicians is a frequent occurrence in individuals with a mental health condition. ${ }^{41,42}$ Furthermore, physical health complications of people with mental health conditions are often neglected by clinicians, resulting in increased mortality rates 
compared to people with solely physical illnesses. ${ }^{41,42}$ Individuals with various mental health conditions are not receiving equitable treatment and tend to receive treatment for only life-threatening diseases ${ }^{41,43}$ The neglect of clinicians' non- probing behaviors and individual's non-disclosure of their physical health state can be attributed to the stigma of having a mental health condition. ${ }^{41-}$ 43 Therefore, the stigma associated with having a mental health condition needs to be addressed across all clinical settings in efforts to reduce the mortality of people with both mental and physical health complications and to provide for a more inclusive environment.

In the current study, all the Hispanic participants refused to disclose their mental health status, due to fear of the negative consequences associated with having a mental health condition. Studies suggest that labeling is the most significant manifestation of stigma. ${ }^{33}$ Labeling often develops into stereotypical beliefs in which members of a community categorize individuals with a mental health condition as being violent, incompetent and responsible for the onset and continuation of their disorder. ${ }^{33} \mathrm{~A}$ study conducted by Sirey and colleagues, suggested that age is a significant predicting factor regarding the perception of stigma. ${ }^{24}$ The study suggested that adults (under 65) are more likely to perceive more stigmas about a mental health condition than older adults. ${ }^{24}$ Older adults that are aware of the manifestations of stigma often alter their behavior accordingly and avoid the mistreatment and discrimination from members in their communities. Additionally, the Hispanic and African American participants, reported solace from their spiritual and religious practices. Cultural practices are often used in times of physical and mental distress, to increase an individual's quality of life. ${ }^{44,45}$ Research suggest that religiosity encourages safer coping mechanisms, enhances pain management, reduces the risk of suicide, improves surgical outcomes and reduces the onset of depression. ${ }^{4,}, 45$ It is imperative for clinicians to utilize a holistic treatment approach to combat the effects of stigma on treatment utilization.

A few of the participants in the current study with past stigmatizing experiences were able to adapt to the adversity of a mental health condition through a supportive network of peers, family and friends. Research shows that increased help seeking behavior from professionals or peers is associated with increased resilience to a mental health condition and decreased stigma. ${ }^{34}$ Individuals become resilient to a mental health condition when they have encountered an experience that granted them with the opportunity needed to overcome stigma; are able to share their experiences of stigma with others; accept the status of their mental health condition, have faith and form meaningful relationships. ${ }^{34,35}$ Due to individuals' beliefs of stigma potentially inhibiting treatment seeking behaviors, it is important that mental health clinicians become aware of the role resiliency plays in seeking professional help. In order to increase the number of individuals seeking mental health treatment, it is imperative to educate the public, those who do and do not currently need mental health treatment about the benefits of mental health treatment. ${ }^{34}$ If individuals with a mental health condition live in a society where treatment for mental health conditions are encouraged rather than stigmatized, it may decrease the large population of undiagnosed, and untreated older adults with a mental health condition.

In the current study, participants who carried these resiliency characteristics were all enrolled in a community engaging project as peer educators. This project created opportunities for them to help others suffering from similar problems. Participation in these community engagement activities allow older adults to learn more about other people and share their values with others, causing them to have increased sense of well-being. ${ }^{36}$ Individuals who have a history of utilizing various mental health treatments gain unique and potentially valuable insights from their treatment experiences, in which they share with appropriate personnel to improve the provision of mental health services. ${ }^{37-39}$ Many older adults in recovery of a mental health condition have made use of their life experiences, problem-solving skills, social skills and formal training to promote independent functioning and social integration amongst their peers who are currently experiencing a mental illness. ${ }^{40}$ Research suggests that older adult's participation in social engagement interventions lead to an increased quality of life, have enhanced self-esteem, self-confidence and selfefficacy. ${ }^{40}$ Older adults who have participated in these programs have worked toward reducing the stigma of having a mental illness, through empathizing and educating others dealing with mental health related issues. ${ }^{40}$ It is important for mental health clinicians to encourage older adults to participate in these activities to improve their quality of life. It is important to note that there are limitations that need to be identified. The research incorporated a small sample of nine participants from the same geographical location. The sample also lacked diversity. This sample consisted of highly educated individuals, which may have affected their knowledge about mental illnesses and their willingness to seek treatment. As a result, findings from the current study cannot be generalized. Despite these limitations, this is one of the only studies which have qualitatively examined perceptions of stigma and experiences of seeking professional mental health services from a vulnerable sample of older adults in recovery from a mental health condition who are currently living with a chronic physical illness. 


\section{CONCLUSIONS}

The stigma of mental illness is a pertinent issue among older adults living with a co-occurring mental health diagnosis. Findings from the current study suggest the need for mental health services catering to our rapidly growing population of older adults. Specifically, health care professionals need to develop solutions to decrease the large number of older adults going undiagnosed and untreated for a mental health condition. Additionally, to avoid stigmatizing experiences from having a mental health condition, more programs educating persons about mental health conditions need to be implemented nation-wide. Due to the evident cultural barriers influencing the treatment utilization behaviors of racial and ethnic minorities, it is important to allocate funding for older adults to service in lay health educator roles. Further research is needed to examine the perceptions of stigma among populations of older adults who have been able to overcome the barriers of stigma, but are not affiliated with community engaging programs, and older adults with different physical conditions. This will allow for more unique resilient strategies to be recreated and taught to other elders in current psychiatric distress.

\section{AKNOWLEDGEMENTS}

We thank Senior Connection Center for their support of the project and for helping identify study participants. We also thank the University of South Florida, Summer Research Institute program for providing the opportunity to conduct important research.

\section{REFERENCES}

1. Penkunas, M. J., Friedman, A., \& Hahn-Smith, S. (2015). Characteristics of older adults with serious mental illness enrolled in a publicly funded in-home mental health treatment program. Home Health Care Management \& Practice. 27(4), 224-229. doi:10.1177/1084822315571531

2. Karel, M. J., Gatz, M., Smyer, M. A. (2012). Aging and mental health in the decade ahead: What psychologists need to know. American Psychologist. (67)3, 184-198. doi:10.1037/a0025393.

3. Webb, A. K., Jacobs-Lawson J.M., Waddell, E. L. (2009) Older adults perceptions of mentally ill older adults. Aging and Mental Health, 13(6), 838-846.

4. Center for Disease Control and Prevention. (2017). https:/ / www.cdc.gov (accessed July 2016)

5. Jeong, H. G., Min B. J., Lim S., Kim T. H., Lee J. J., Park J. H. (2013). Plasman adiponectin elevation in elderly individuals with subsyndromal depression. Psychoneuroendocrinology 37(7), 948-955. doi: 10.1016/j.psyneuen.2011.11.002.

6. O'connor, D., Little, F., \& McManus, R. (2009). Elders with Serious Mental Illness: Lost Opportunities and New Policy Options. Journal of Aging \& Social Policy, 21(2), 144-158. doi:10.1080/08959420902733090

7. Yunming, L., Changsheng, C., Haibo, T., Wenjun, C., Shanhong, F., Yan, M., \& Qianzhen, H. (2012). Prevalence and risk factors for depression in older people in xi'an china: A community-based study. Int. J. Geriat. Psychiatry International Journal of Geriatric Psychiatry, 27(1), 31-39. doi:10.1002/gps.2685

8. World Health Organization. (2017). Depression. http:// www.who.int/ mediacentre/factsheets/fs369/en (accessed July 2016)

9. American Psychiatric Association. (2013). Diagnostic and statistical manual of mental disorders (5 ${ }^{\text {th }}$ ed.). Arlington, VA: American Psychiatric Publishing

10. Zivin, K., Llewellyn, D. J., Lang, I. A., Vijan, S., Kabeto, M. U., Miller, E. M., \& Langa, K. M. (2010). Depression Among Older Adults in the United States and England. The American Journal of Geriatric Psychiatry, 18(11), 1036-1044. doi:10.1097/jgp.0b013e3181dba6d2

11. Sickel, A. E., Seacot J. D., Nabors, N. A. (2014). Mental health stigma update: A review of consequences. Advances in Mental Health. 12(3), 202-215. doi:abs/10.1080/18374905.2014.11081898

12. Zegwaard, M., Aarsten, M., Cuijpers, P,. \& Grypdonck, M. (2015). Review: A conceptual model of perceived burden of informal caregivers for older persons with a severe functional psychiatric syndrome and concomitant problematic behaviour. Journal of Clinical Nursing, 20(15-16.) 2233-2258. doi: 10.1111/j.1365-2702.2010.03524

13. NAMI (2016). National alliance on mental illness-:Mental health support, education and advocacy. http:/ / wmw.nami.org (accessed July 2016)

14. Wainberg, M. L., Cournos, F., Wall, M. M., Pala, A. N., Mann, C. G., Pinto, D., Mckinnon, K. (2016). Mental illness sexual stigma: Implications for health and recovery. Psychiatric Rehabilitation Journal. bttps:// wnw.ncbi.nlm.nih.gov/pubmed/27030909

15. Thornicroft, G. (2011). Physical health disparities and mental illness: The scandal of premature mortality. British Journal of Psychiatry, 199(06), 441-442. doi: 10.1192/bjp.bp.111.092718

16. Brown, N. B., \& Bruce, S. E. (2016). Stigma, career worry, and mental illness symptomatology: Factors influencing treatmentseeking for operation enduring freedom and operation Iraqi freedom soldiers and veterans. Psychological Trauma: Theory, Research, Practice, and Policy, 8(3), 276-283. doi:10.1037/tra0000082

17. Kulesza, M., Raguram, R., \& Rao, D. (2014). Perceived mental health related stigma, gender, and depressive symptom severity in a psychiatric facility in South India. Asian Journal of Psychiatry, 9, 73-77. doi:10.1016/j.ajp.2014.03.005

18. Drapalski, A. L., Lucksted, A. L., Perrin, P. B., Aakre, J. M., Brown, C. H., DeForge, B. R., \& Boyd, J. E. (2013). A model of internalized stigma and its effects on people with mental illness. Psychiatric Services, 64(3), 264-269.

doi/pdf/10.1176/appi.ps.001322012 
19. Dharitri R., Rao S. N., Kalyanansunduram S. (2015). Stigma of mental illness: An intervention study to reduce the impact in the community. Indian Journal of Psychiatry, 57(2), 165-173. doi: 10.4103/0019-5545.158175

20. Komiti A., Judd F., Jackson H. (2006). The influence of stigma and attitudes on seeking help from a GP from mental health problems: A rural context. Social Psychiatry and Psychiatric Epidemiology, 41(9), 738-745. Retrieved from bttps:// www.ncbi.nlm.nih.gov/pubmed/16819564

21. Corrigan, P. W., Druss, B. G., Perlick D. A. (2014). The impact of mental illness stigma on seeking and participating in mental health care. Psychological Science in the Public Interest, 15(2), 37-70. doi: 10.1177/15291000614531398.

22. Corrigan, P. W., Rusch, N., Wassel, A., Michaels, P., Larson, J. E., Olschewski, M., Wilkniss, S., Batia, K. (2009). Self-stigma, group identification, perceived legitimacy of discrimination and mental health service use. British Journal of Psychiatry. 195(6), 551-552. doi: 10.1192/bjp.bp.109.067157.

23. Roeloffs, C., Sherbourne, C., Unutzer, J., Fink, A., Tang, L., Wells, K. (2003). Stigma and depression among primary care patients. General Hospital Psychiatry. 25(5), 311-315. Retrieved from https:// www.ncbi.nlm.nih.gov/pubmed/12972221

24. Sirey J. A., Bruce M. L., Alexopoulos, G. S. (2001). Perceived stigma as a predictor of treatment discontinuation in young and older outpatients with depression. American Journal of Psychiatry, 158(3), 479-481. https://wnw.ncbi.nlm.nih.gov/pubmed/11229992

25. Braun, V., \& Clarke, V. (2006). Using thematic analysis in psychology. Qualitative Research in Psychology, 3(2), 77-101. doi:10.1191-1478088706qp0630a

26. O'keeffe, J., Buytaert, W., Mijic, A., Brozovic, N., \& Sinha, R. (2015). The use of semi-structured interviews for the characterisation of farmer irrigation practices. Hydrology and Earth System Sciences Discussions Hydrol. Earth Syst. Sci. Discuss., 12(8), 8221-8246. doi:10.5194/ hessd-12-8221-2015

27. Sofaer S. (1999). Qualitative methods: What are they and why use them? Health Services Research. 34(5), 1101-1118. bttps:/ / www.ncbi.nlm.nih.gov/pmc/articles/PMC1089055/

28. Barrera, I., Schulz, C. H., Rodriguez, S. A., Gonzalez, C. J., \& Acosta, C. A. (2013). Mexican-American perceptions of the causes of mental distress. Social Work in Mental Health, 11(3), 223-248. doi:10.1080/15332985.2013.774922

29. Mizock, L., \& Russinova, Z. (2013). Racial and ethnic cultural factors in the process of acceptance of mental Illness. Rehabilitation Counseling Bulletin, 56(4), 229-239. doi:10.1177/0034355213475823

30. Thoman, L. V., \& Suris, A. (2004). Acculturation and acculturative stress as predictors of psychological distress and qualityof-life functioning in Hispanic psychiatric patients. Hispanic Journal of Behavioral Sciences, 26(3), 293-311. doi:pdf/10.1177/0739986304267993

31. Hirai, M., Vernon L. L., Popan J. R., Clum, G. A. (2015). Acculturation and enculturation, stigma toward psychological disorder, and treatment preferences in a Mexican American sample: The role of education in reducing stigma. Journal of Latina/ o Psychology, 3(2), 88-102. http:/ / dx.doi.org/10.1037/lat0000035

32. Nxumalo, C. T., Mchunu G. G. (2017). Exploring the stigma related experiences of family members of person with mental illness in a selected community in the iLembe district, KwaZulu-Natal. Health SA Gesondheid, 22, $202-212$. bttps:// doi.org/10.1016/j.hsag.2017.02.002

33. Corrigan, P. (2004). How stigma interferes with mental health care. American Psychological Association. $59(7), 614-625$. doi:10.1037/0003-066X.59.7.614

34. Crowe, A., Averett, P., \& Glass, J. S. (2016). Mental illness stigma, psychological resilience, and help seeking: What are the relationships? Mental Health \& Prevention, 4(2), 63-68. doi:10.1016/j.mhp.2015.12.001

35. Edward, K. L., Welch A., Chater K. (2009). The phenomenon of resilience as described by adults who have experienced mental illness. Journal of Advanced Nursing, 65(3), 587-595. doi: 10.1111/j.1365-2648.2008.04912. .x

36. Stukas A. A., Hoye R., Nicholson M., Brown, K. M., Aisbett L. (2016). Motivations to volunteer and their association with volunteers' well-being 45(1), 112-132. doi.org/10.1177/0899764014561122

37. Felton, C., Stastny, P., Shern, D., Blanch, A., Donahue, S., Knight, E., \& Brown, C. (1995). Consumers as peer specialists on intensive case management teams: Impact on client outcomes. Psychiatric Services, 46(10), 1037-1044. doi:10.1176/ps.46.10.1037

38. McGill C. W., Patterson C. J. (1990). Former patients as peer counselors on locked psychiatric inpatient units. Hospital Community Psychiatry, 41(9), 1017-1019. doi: 10.1176/ps.21.0.1017

39. Segal, S., Silverman, C., \& Temkin, T. (1993). Empowerment and self-help agency practice for people with mental disabilities. Social Work, 38, 705-712.

40. Conner, K. O., Ward C. J., Reynodls C. F., Brown C., \& Johnson, A. J., (2016). Giving back to their communities: The benefit of peer education as productive engagement for depressed elders of color. Paper presented at the 2016 NIMH Mental Health Services Research Conference in Washington, DC.

41. Lawrence, D. M., Holman, C. D., Jablensky A., \& Hobbs M. S. (2003). Death rate from ischaemic heart disease in western Australian psychiatric patients 1980-1998. British Journal of Psychiatry, 182, 31-36.

42. Leucht, S., Burkard T., Henderson, J., Maj, M., Satorius N. (2007). Physical illness and schizophrenia: A review of the literature. Acta Psychiatr Scand, 116, 317-333. doi: 10.1111/j.1600-0447.2007.01095.x 
43. Corker E., Brown, J., Henderson C. (2016). How does self-stigma differ across people with psychiatric diagnoses and rheumatoid arthritis, and how does it impact on self-esteem and empowerment? Psychology, Health \& Medicine, 21(8), 993-1005. doi: 10.1080/13548506.2016.1139139

44. Larson, D., \& Larson, S. (2003). Spirituality's potential relevance to physical and emotional health: A brief review of quantitative research. Journal of Psychology and Theology, 31, 37-51.

45. Linders E. H., Lancaster B. L. (2013). Sacred illness: Exploring transpersonal aspects in physical affliction and the role of the body in spiritual development. Mental Health, Religion \& Culture, 16(10), 991-1008. doi: 10.1080/13674676.2012.728578

\section{ABOUT STUDENT AUTHOR}

Angela J. Johnson is a recent graduate from Mary Baldwin University in Staunton, Virginia, where she received her Bachelor of Science in Psychology. At Mary Baldwin, Angela was an active member of the Student Government Association, Psi Chi and Global Honors Scholars. In the future, Angela aspires to further her education in Public Health in hopes to continue conducting community research on mental health and older adults.

\section{PRESS SUMMARY}

Older adults are a vulnerable population who are more susceptible to developing mental health conditions, and the symptoms are often made worse by the co-occurrence of various physical health complications. The present study provides a deeper understanding of the stigmatizing obstacles this population has overcome in their journey toward recovery of a mental health condition. 